\title{
CONTEMPORARY MORPHOGENETIC PROCESSES IN THE WEST PAMIRS
}

The Pamirs is a massive covering an area of some 70 thousand sq.km., exceeding on the average altitude of $4,000 \mathrm{~m}$ a.s.l. Its geological structure and tectonics are very complex. It was ultimately risen up in the Alpine orogenesis, but its ridges are countinuously being raised $(55 \mathrm{~mm} / \mathrm{year}$; Bondarev 1976). This is accompanied by high seismism.

The Pamirs belongs today to strongly glaciated mountain massives. There are about 1100 glaciers here that can be classified among four main morphological types: valley, cirque, hanging and apron. This is determined by its central location on the continent, dominating western atmospheric circulation, absolute altitude and segmentation of the mountains. The altitude of the equilibrium-line depends, mainly, on the above-mentioned factors. In the western part it reaches $3,600 \mathrm{~m}$ a.s.l., while in the eastern one $5,250 \mathrm{~m}$ (A.G. Sannikov 1982).

In order to present the contemporary relief-forming processes in the West Pamirs the use has been made of the observations made in the region of Communism Peak*, as well as of some data from literature. The area under investigation comprises 300 sq.km covering fragments of the ridges of the Academy of Sciences Range and the Peter I Range, with the highest peak in the Pamirs and at the same time in the Commonwealth of Independent Nations - Communism Peak $(7,495 \mathrm{~m})$, as well as the third highest peak - Korzhenevskoy Peak ( $7.105 \mathrm{~m}$ ) (Fig.1). It is characterized by extremely suitable conditions for the existence of glaciers, which constitute $53.4 \%$ of the area there.

Due to erosion, transport and accumulation, glaciers are an important factor shaping a contemporary mountain relief. They transport the masses of rock material detached from the valley slopes and bottoms, as well as that coming from the walls and mountain sides, thus deepening and levelling their profiles. The material is accumulated in the shape of terminal, lateral and medial moraines. The most conspicuous aspects of this operation in the region of Communism Peak are belts of lateral moraines alongside almost all the valley glaciers: Fortambek, Traube, Moskvin, Val- 
ter, as well as medial moraines of the glaciers: Traube, Valter and Fortambek (Fig.1). Due to its high inclination, the area has no suitable conditions for the emergence of terminal morainic embankments. Their remains have only been observed in front of the Cetlin glacier. Exceptional dynamics of glacial waters and mass-movement processes cause crushing, selection and further transport of the material supplied by the above-mentioned glacier, thus enriching the Valter glacier. Tongues of the majority of glaciers of the West Pamirs, especially of the valley type, such as Valter, Fortambek, Mushketov, are densely covered by the layer of debris. The so-called "contaminated" glaciers constitute $11.5 \%$ of ice-covered surface of the area under investigation. This is the effect of intensive operation of contemporary relief-forming processes. Another phenomenon connected with glaciers is an avalanche erosion. It occurs on higly inclined slopes with vast accumulation of the masses of snow and ice, causing their erosion. The material is deposited at the outlet of the gullies in the form of the cones. The processes have been repeatedly recorded on NW slopes of Communism Peak, SE slopes of Korzhenevskoy Peak, and on W slopes of Khokhlov and Izviestii Peaks.

Unglaciated surface of the West Pamirs has suitable conditions for intensive formation of young relief, by the mass-movements in particular. Highly inclined slopes, considerable denivelation, 24 hour temperature amplitudes, winds of high velocity, absence of plant cover, as well as seismic activity pave the way for relief-forming processes.

Rock walls are mainly transformed by detachment and falling. The effect of short-lived processes can be seen as taluses at the foothills. The most intensive processes were recorded on the $W$ side of the Academy of Sciences Range and on the S Range of Peter I (Fig.1). The processes of falling away, enriched with sliding down, shape the rock slopes of the peaks: Chetyriokh, Izviestii, and Korzhenevskoy. Slopes with rock debris are subject to washing (dispersed and linear), sliding, crawling down and earth-flow. Debris covers also vast parts of $S$ slopes of Chetyriokh Peak, SE slopes of Korzhenevskoy Peak, $\mathrm{N}$ and $\mathrm{E}$ slopes of NKWD Peak ${ }^{*}$. In their region talus cones can often be encountered, being the result of simultaneous gravitational, avalanche and water accumulation. The largest form of this type was noticed at the foothills of SE wall of Korzhenevskoy Peak (Fig.1). The newly emerging accumulation forms, such as cones, lateral moraines, are usually not the final effect, but they continue to be subject to transformation.

Fig. 1. Contemporary morphogenetic process in the region of Communism Peak; $a-$ peaks, $b$ - ridges, $c$ - gullies, $d$ - rock walls shaped by detachment and falling away, e - rocky slopes shaped by falling away, sliding down and avalanche erosion, $\mathrm{f}$ - slopes with rock debris shaped by washing, sliding, crawling down and earth-now, $\mathrm{g}$ - talus cones created due to gravitational, avalanche and water accumulation, $h-$ glacial cirques, $i-$ glaciers, $j-$ glaciers with surface moraine, $\mathbf{k}$ - ramparts of lateral moraines, 1 - ramparts of medial moraines, $\mathrm{m}-$ bottoms of old glacial valleys, $\mathrm{n}-$ glacial river channels, $\mathbf{o}-$ glacial rivers 


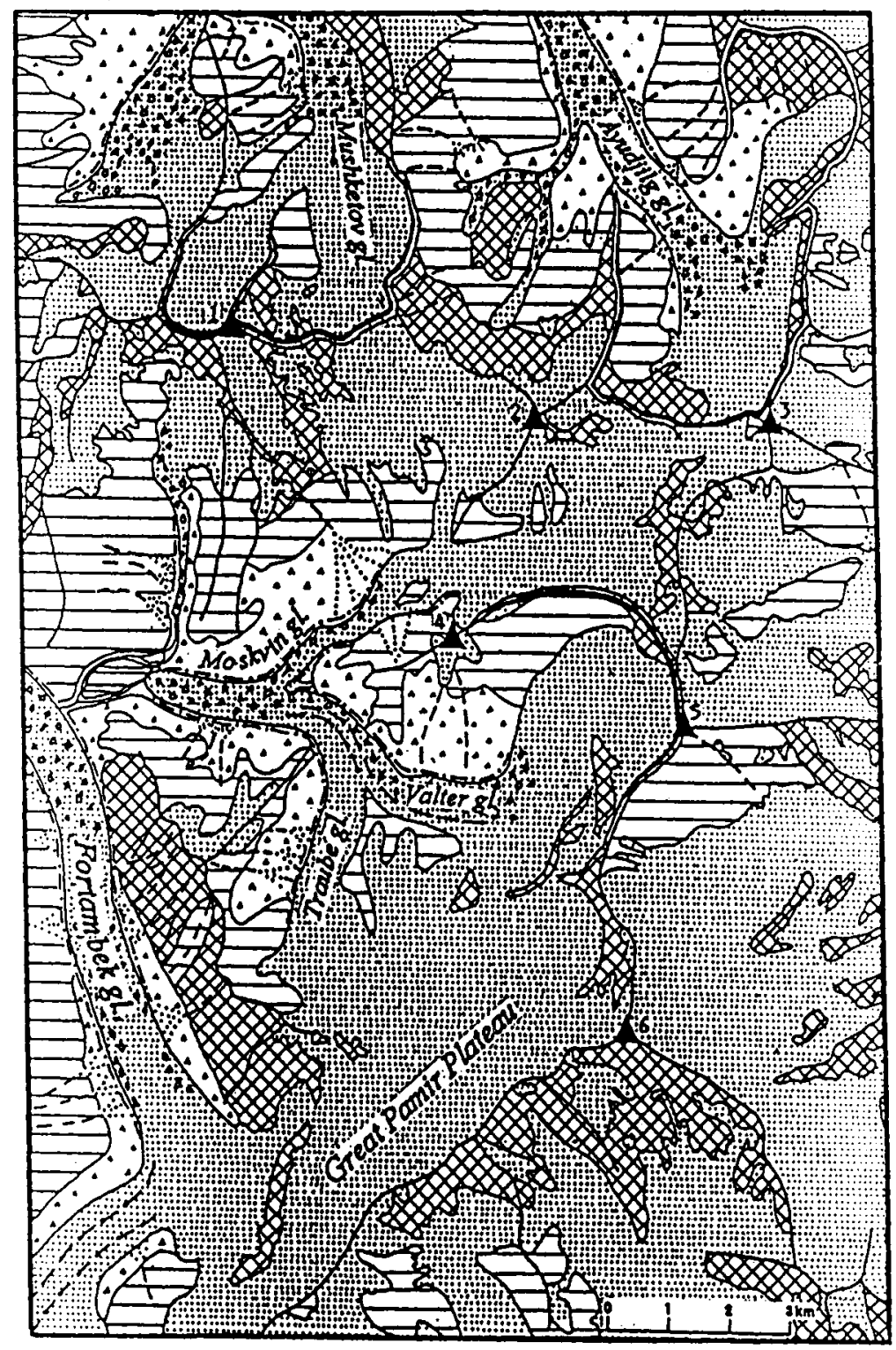
a $\Delta$
ก
1. Pask Korzhanevakoy (7205)
b $\simeq$
1 计
2. Paak Chatyrlokh (6299)
¿ 8
3 Pingas
3. Peak Ahaad1-Donlsh (6665)
c $\square$
$k=$
4. Peak Vorober (5691)
14
$-\infty$
5. Pakk Izvest11 (6840)
g :
n $>$
6. Peak Communisn (7495) 
The analysis of morphogenetic processes in the region of Communism Peak shows that the area, like all the high mountains region of the West Pamirs, is currently undergoing intensive modelling. Young relief is being transformed by natural processes. Man reached only some regions here, and changes caused by his activity are not dangerous as yet.

- Proper names currently used in Tajikistan.

\section{REFERENCES}

B ond a rev L.G., 1976, Viyanie tektoniki na evolucyu lednikov y formirovanye glacyalnovo relefa, Frunze.

Sannik ov A.G., 1982, Firnovaya linya (in:) Tajikistan, Priroda y prirodnye resursi, Donish, Dushanbe. 